\title{
A Multicriteria Approach for the Optimal Location of Gasoline Stations Being Transformed as Self-Service in Taiwan
}

\author{
Sheng-Pen Wang, ${ }^{1}$ Hsing-Chen Lee, ${ }^{2}$ and Yu-Kuang Hsieh ${ }^{2}$ \\ ${ }^{1}$ Department of Industrial and Business Management, Chang Gung University, 259 Wenhua 1st Road, Guishan District, \\ Taoyuan 333, Taiwan \\ ${ }^{2}$ Graduate Institute of Business and Management, Chang Gung University, 259 Wenhua 1st Road, Guishan District, \\ Taoyuan 333, Taiwan
}

Correspondence should be addressed to Yu-Kuang Hsieh; d9840201@stmail.cgu.edu.tw

Received 7 October 2015; Revised 27 February 2016; Accepted 17 March 2016

Academic Editor: Zhen-Lai Han

Copyright (C) 2016 Sheng-Pen Wang et al. This is an open access article distributed under the Creative Commons Attribution License, which permits unrestricted use, distribution, and reproduction in any medium, provided the original work is properly cited.

\begin{abstract}
Location selection significantly influences business success. In particular, location selection for the fuel stations is characterized by constraints on investment in facilities and by criteria that involve a series of social utilities. Recently, a leading fuel company in Taiwan initiated transforming its traditional gas stations into self-service. However, it is difficult to select an existing station to be transformed as self-service because there are many conflicting goals in the problem of location selection. In this paper, we apply a multicriteria approach, integrating analytic hierarchy process (AHP) and multichoice goal programming (MCGP), to obtain an appropriate gas station from many alternative locations that best suit the preferences of decision-makers in the case company. This study incorporates the weights obtained from AHP to set multiple aspirations in MCGP for ranking each candidate location. The results show that, under multiple quantitative and qualitative factors in the selection process, our proposed model is more scientific and efficient than unaided methods in finding a suitable location within a shorter evaluation time.
\end{abstract}

\section{Introduction}

The number of gas stations in Taiwan rapidly increased from 1,884 in 1999 up to 2,504 in 2014, reaching a peak of 2,629 in 2009. According to the services offered, there are two types of gas stations: full service and self-service. Operation on selfservice gas stations in Taiwan was first launched in 2006, though nowadays most of the gas stations still provide full service, where many part-time workers are hired to check the liquids and clean the windshields of vehicles. However, legal restrictions prevent most part-time workers from becoming full-time employees. This fact leads to high turnover rate with its associated management challenges to the operations of a gas station. On the other hand, self-service gas stations require fewer human resources; they not only reduce the labor cost but also lessen the need to recruit and train employees. Furthermore, savings on labor expenses can be partially reimbursed by offering customers lower prices, and self-service thus increases customers' usage intention. In the long run, self-service hence offers the best overall solution to the operations of gas stations.

This research is motivated by a fuel company in southern Taiwan, which planned on transforming an existing fullservice gas station into a self-service one. A good location is naturally important to operational success since it determines the sites equipped with better facilities for providing customers with greater services. However, selecting an originally full-service gas station to be transformed to and upgraded as a self-service one is a tough decision problem. Oftentimes, it is simply evaluated by past experience from a group of experts and, in most cases, these traditional methods may not result in the best decision as such intuition judgment can be biased by decision-makers' emotion or personal opinions on the plentiful information. A structured and scientific method is thus necessary and important. This study proposes an evaluation model, integrating analytic hierarchy process (AHP) with multichoice goal programming (MCGP), as decision aid to help the case company select a suitable 
location in consideration of both qualitative and quantitative criteria. The proposed multicriteria model applies appropriate weights from AHP on the objective function of MCGP, and it can effectively aid decision-makers (DMs) in decisionmaking and successfully provide the case company with the most suitable combination of DMs' preferences in selecting a gas station from many alternative candidates.

Some literature in location selection aims to optimize a site for profit maximization and/or for distance minimization by using geographical information system (GIS). For example, Adsavakulchai and Huntula [1] integrated GIS and spatial modeling in selecting an optimal station for natural gas vehicles in Thailand. Aslani and Alesheikh [2] adopted GIS in site selection for small gas stations. On the other hand, several relevant studies considered qualitative criteria. For example, Tzeng et al. [3] adopted the AHP approach to select a restaurant location that considers economics, transportation, competition, commercial area, and environment factors. Aras et al. [4] used AHP to determine the location for a wind observation station that takes five qualitative criteria into consideration including cost, topography, infrastructure, security, and convenience of transportation. Wong and Li [5] conducted an AHP survey to conclude that "work efficiency" is perceived as the most important core selection criterion for various intelligent building systems. Additionally, in this journal, Uyan [6] determined the suitable site selection for solar farms by using GIS and AHP in Karapinar region in Turkey. With respect to AHP method, DMs can determine criterion weights effectively; however, only few candidate locations can be evaluated by these criteria because of the complex interrelations among them. Therefore, to develop an efficient tool for improving the efficiency of location selection becomes an important issue.

Some studies applied mathematical methods to the problem of location selection with quantitative criteria. For example, Jovanovic [7] formulated an integer programming model to select a location with suitable size for a new distribution transformer by calculating annual investment costs, voltage drops, load of feeders, and substations. Cheng and $\mathrm{Li}$ [8] adopted the methods of data envelopment analysis and binary linear programming to decide the valuable project location for investment. However, mathematical programming methods cannot solve the problem of location selection with qualitative criteria, and they cannot provide DMs with the precise weights of the objective function for each goal in solving multiple objective decision-making problems.

Charnes and Cooper [9] developed goal programming (GP) on the basis of minimizing the total deviations from each goal. Since then, GP has been a popular method in handling problems with multiple purposes to be fulfilled. In this journal, San Cristóbal [10] proposed a novel GP model to address the problem of how to locate five renewable energy plants for power generation in five places in the north of Spain. However, deciding the specific target value of each goal is sometimes not easy for a DM because only partial information can be obtained in an uncertain environment. For example, in selecting a gas station to be transformed as self-service, DMs may require a goal with multiple aspiration levels in improving customers' swipe rate and attracting neighborhood acceptance. Since this type of multichoice problem, where one goal is mapped into multiple aspiration levels addressed by "the more/higher is better" and/or "the less/lower is better," could not be solved by simply using the GP method, Chang [11] proposed the multichoice goal programming (MCGP) which enables DMs to find the best achievement level satisfying multiobjective functions.

We here integrate MCGP with AHP to achieve a multicriteria approach for selecting the "best" gas station to be transformed as self-service. Using AHP, DMs can effectively determine appropriate weights for each goal. By applying these weights in the objective function of MCGP, DMs can efficiently evaluate many candidates and rank them by considering multiple aspiration levels. In the recent years, some studies adopt AHP and MCGP in the selection problem. Liao and Kao [12] integrated Taguchi loss function, AHP, and MCGP in selecting a supplier. Ho et al. [13] utilized AHPMCGP approach to select a suitable location for coffee shop or restaurant operations. Lin et al. [14] proposed an AHPMCGP evaluation model as decision aid to help DMs obtain appropriate online tools considering the time limitations of teachers and students. Accordingly, this study takes all advantages of the best characteristics of AHP and MCGP and considers simultaneously both qualitative and quantitative criteria in determining the most suitable gas station for being transformed as self-service.

\section{Criteria for Selecting a Gas Station}

The case study company is a leading petroleum firm in Taiwan, producing and selling oil products to domestic and international clients in the industrial and consumer markets. Currently, only approximately $5 \%$ of the case company's gas stations are equipped with the computerized facility for self-service. Knowing that self-service gas stations not only attract customers but also make it easy to manage and recruit part-time employees, the company would like to carry out the selection process as an example to transform all the remaining full-service stations into self-service ones in the long run.

From literature review, the criteria of site selection for gas stations include qualitative criteria such as traffic and environment in Aslani and Alesheikh [2] and quantitative ones such as lot size, waiting time, and average swipe rate in Adsavakulchai and Huntula [1]. To identify the location selection criteria for this case company, we consulted with the company's general managers and gas station masters. Besides, to satisfy the government requirements on fuel operations and sustainable energy, we considered as well those relevant regulations from local and national laws. The final AHP hierarchy of location selection used in this study is constructed as shown in Figure 1.

The first level is the ultimate goal to select the most suitable gas station for being transformed as self-service. Level 2 includes three criteria: traffic, environment, and building, which are all perceived to be the important cores in site selection. Finally, the third level lists ten subcriteria, which are categorized into some criterion of traffic, environment, 


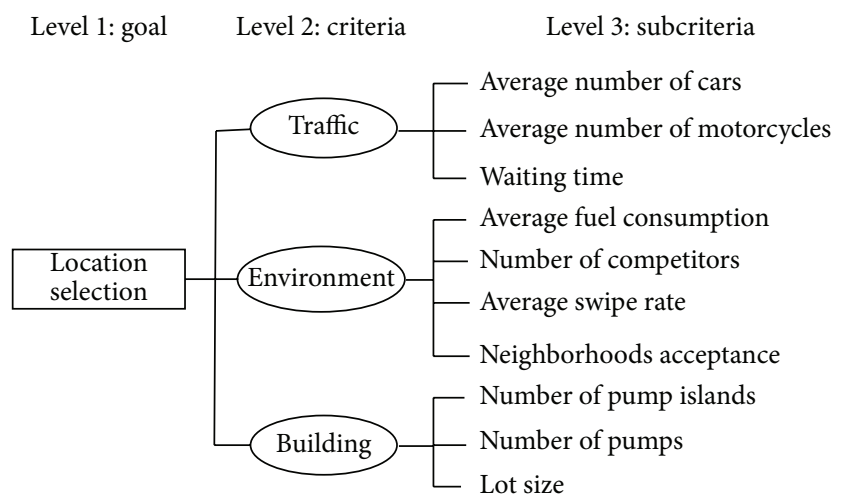

FIGURE 1: Hierarchical structure to select a gas station for starting self-service.

TABLE 1: Definitions of the ten subcriteria for the case problem.

\begin{tabular}{|c|c|}
\hline Subcriterion & Definition \\
\hline $\begin{array}{l}\text { SC1: average number } \\
\text { of cars }\end{array}$ & Average number of cars per day \\
\hline $\begin{array}{l}\text { SC2: average number } \\
\text { of motorcycles }\end{array}$ & $\begin{array}{l}\text { Average number of motorcycles per } \\
\text { day }\end{array}$ \\
\hline SC3: waiting time & $\begin{array}{l}\text { Customer's average waiting time in } \\
\text { line for refueling ( } \mathrm{min} \text { ) }\end{array}$ \\
\hline $\begin{array}{l}\text { SC4: average fuel } \\
\text { consumption }\end{array}$ & $\begin{array}{l}\text { The amount of fuel consumed by } \\
\text { the vehicle per day }(\mathrm{dL})\end{array}$ \\
\hline $\begin{array}{l}\text { SC5: number of } \\
\text { competitors }\end{array}$ & $\begin{array}{l}\text { The number of similar gas services } \\
\text { within } 2 \text { kilometers }\end{array}$ \\
\hline $\begin{array}{l}\text { SC6: average swipe } \\
\text { rate }\end{array}$ & $\begin{array}{l}\text { The percentage of swipes utilized by } \\
\text { the customers per day (\%) }\end{array}$ \\
\hline $\begin{array}{l}\text { SC7: neighborhood } \\
\text { acceptance }\end{array}$ & $\begin{array}{l}\text { The percentage of neighbors willing } \\
\text { to accept or use the new technology } \\
(\%)\end{array}$ \\
\hline $\begin{array}{l}\text { SC8: number of gas } \\
\text { pump islands }\end{array}$ & $\begin{array}{l}\text { Number of gas pump islands in the } \\
\text { gas station }\end{array}$ \\
\hline $\begin{array}{l}\text { SC9: number of gas } \\
\text { pumps }\end{array}$ & $\begin{array}{l}\text { Total number of gas pumps in the } \\
\text { gas station }\end{array}$ \\
\hline $\begin{array}{l}\text { SC10: floor area or lot } \\
\text { size }\end{array}$ & The floor size of the gas station $\left(\mathrm{m}^{2}\right)$ \\
\hline
\end{tabular}

or building. Specific definitions of these ten subcriteria are summarized in Table 1.

Data for this study were obtained from the city branch managers of the oil company, where 8 candidate gas stations around the city were identified and denoted as $\mathrm{ST}_{1}, \mathrm{ST}_{2}, \ldots, \mathrm{ST}_{7}$, and $\mathrm{ST}_{8}$. Information about every subcriterion for each candidate station is shown in Table 2. For example, there are about 525 cars (in SC1) and 1294 motorcycles (in SC2) refueling at the first candidate station $\mathrm{ST}_{1}$, which owns 6 gas pumps (in SC9) in total and whose floor size is 1524 square meters (in SC10).

\section{The Proposed Method}

This study integrates AHP and MCGP to solve the problem of selecting a gas station to be transformed as self-service.
TABLE 2: Data information of each subcriterion for all candidate stations.

\begin{tabular}{lcccccccc}
\hline \multicolumn{8}{c}{ Candidate station } \\
& $\mathrm{ST}_{1}$ & $\mathrm{ST}_{2}$ & $\mathrm{ST}_{3}$ & $\mathrm{ST}_{4}$ & $\mathrm{ST}_{5}$ & $\mathrm{ST}_{6}$ & $\mathrm{ST}_{7}$ & $\mathrm{ST}_{8}$ \\
\hline $\mathrm{SC} 1$ & 525 & 1800 & 451 & 1291 & 1020 & 550 & 606 & 475 \\
$\mathrm{SC} 2$ & 1294 & 2482 & 2700 & 2321 & 4311 & 2555 & 1252 & 1093 \\
$\mathrm{SC} 3$ & 2 & 5 & 4 & 4 & 4 & 3 & 3 & 6 \\
\hline SC4 & 20479 & 23197 & 21821 & 40378 & 39374 & 31189 & 23025 & 36962 \\
SC5 & 5 & 10 & 3 & 6 & 13 & 3 & 2 & 3 \\
SC6 & $12 \%$ & $14 \%$ & $\underline{\mathbf{6}} \%$ & $10 \%$ & $11 \%$ & $11 \%$ & $11 \%$ & $13 \%$ \\
SC7 & $40 \%$ & $60 \%$ & $40 \%$ & $70 \%$ & $60 \%$ & $30 \%$ & $40 \%$ & $50 \%$ \\
\hline SC8 & 4 & 5 & 5 & 3 & 3 & $\mathbf{2}$ & 4 & 4 \\
SC9 & 6 & 6 & 5 & 6 & 6 & 4 & 6 & 6 \\
SC10 & 1524 & 1274 & 1870 & 2035 & 1631 & 1159 & 1171 & 1120 \\
\hline
\end{tabular}

We first use AHP approach to obtain the weights for the qualitative evaluation factors based on different location purposes. Then, the MCGP method is used for the quantitative evaluation to achieve the ranking list of all candidate locations.

3.1. Analytic Hierarchy Process (AHP). Introduced by Saaty [15], the AHP is a mathematical multicriteria decisionmaking model to deal with the complex problems with quantitative and qualitative data through constructing hierarchies. The AHP method consists of three major steps as follows. The first is problem description: the problem is resolved into elements, which are grouped at different levels in a chain hierarchy, and each element is further decomposed into subcriteria until the lowest level of the hierarchy is reached. The second is comparative analysis: the relative importance of each element at a particular level is measured by a pairwise comparison procedure. DMs must make a series of pairwise comparisons on the basis of nine scales. The third is the synthesis of priorities: the priorities of each element are synthesized to establish the overall priorities for the decision alternatives, and the priority weights of the elements at each level are computed using eigenvectors.

The AHP method with pairwise comparison is used to measure the importance for every factor, either tangible or intangible, and a matrix is generated as a result of pairwise comparisons and criteria weights are reached as a result of these calculations. Also, it is possible to determine the consistency ratio (CR) of decisions, and CR reveals the random probability of values being obtained in a pairwise comparison matrix. If $\mathrm{CR} \leq 0.1$, the degree of consistency is satisfactory; otherwise, there are serious inconsistencies and the AHP may not yield meaningful results [16].

3.2. Multichoice Goal Programming (MCGP). GP is an analytical approach devised to address decision-making problems where targets have been assigned to all the attributes and where DMs are interested in minimizing the nonachievement of the corresponding goals. The MCGP approach, proposed by Chang [11], allows DMs to set multichoice aspiration levels for each goal (i.e., one goal mapping multiple aspiration 
TABLE 3: Pairwise comparison matrix for criteria at level 2.

\begin{tabular}{lcccc}
\hline Criteria (facets) & Traffic & Environment & Building & Weight \\
\hline Traffic & 1 & $1 / 2$ & 2 & 0.311 \\
Environment & 2 & 1 & 2 & 0.493 \\
Building & $1 / 2$ & $1 / 2$ & 1 & 0.196 \\
\hline
\end{tabular}

levels) to avoid underestimation of the decision. The achievement function of MCGP can be expressed as follows:

$$
\begin{array}{ll}
\operatorname{Min} & \sum_{i=1}^{n}\left(w_{i} d_{i}^{+}+d_{i}^{-}\right)+\sum_{i=1}^{n}\left(e_{i}^{+}+e_{i}^{-}\right) \\
& f_{i}(\vec{x})-d_{i}^{+}+d_{i}^{-}=g_{i}, \\
& i=1,2, \ldots, n, \vec{x}=\left(x_{1}, x_{2}, \ldots, x_{m}\right), \\
& g_{i}-e_{i}^{+}+e_{i}^{-}=g_{i, \max }, \quad i=1,2, \ldots, n, \\
& g_{i, \min } \leq g_{i} \leq g_{i, \max }, \quad i=1,2, \ldots, n, \\
& d_{i}^{+}, d_{i}^{-}, e_{i}^{+}, e_{i}^{-} \geq 0, \quad i=1,2, \ldots, n,
\end{array}
$$

where $w_{i}$ are (positive) weights obtained from AHP attached to positive deviations $d_{i}^{+}$in the objective function only; $d_{i}^{+}$ and $d_{i}^{-}$are the over- and underachievements of the $i$ th goal $(i=1,2, \ldots, n)$, and there are $n$ goals. $f_{i}(\vec{x})$ is a linear function of $\left(x_{1}, x_{2}, \ldots, x_{n}\right)$ for the $i$ th goal and the binary variable $\vec{x}=\left(x_{1}, x_{2}, \ldots, x_{m}\right)$ represents the feasibility of the $m$ potential alternatives. $g_{i}$ is the aspiration level of the $i$ th goal; $e_{i}^{+}$and $e_{i}^{-}$are the positive and negative deviations attached to $\left|g_{i}-g_{i, \max }\right|$, and $g_{i \text {,min }}$ and $g_{i \text {,max }}$ are the lower and upper bounds of $g_{i}$, respectively. MCGP is a linear form of GP, where $g_{i}$ will be forced to approach $g_{i, \max }$ as close as possible because $e_{i}^{+}$and $e_{i}^{-}$should be minimized in the objective function; similarly, $f_{i}(\vec{x})$ will be forced to approach $g_{i}$ as close as possible because the weighted deviations $w_{i} d_{i}^{+}+$ $d_{i}^{-}$should be minimized.

\section{The Solution Procedure}

We first use AHP approach to obtain the weights for location criteria in the hierarchy and then integrate these weights in the objection function of MCGP model to set up multiple aspiration levels for each goal.

4.1. Weights from AHP. The software, Expert Choice, was used to calculate the weight of each location criterion on the AHP hierarchy. Table 3 shows the pairwise comparison between criteria of traffic, environment, or building at the second level. The associated consistency ratio is 0.046 , which is less than 0.1 , and this means the judgment is consistent and the weights shown in Table 3 are acceptable as suggested by Saaty [16]. Table 3 reveals that the most important facet in selecting a location for a self-service gas station is environment, with the highest weight of 0.493 . The traffic criterion takes the second place with a weight of 0.311 , finally followed by the building facet. The results suggest that DMs may need to pay more attention to the environmental issues, which outperform the traffic factors in site selection.

The pairwise comparison matrices for the subcriteria at level 3 within "traffic," "environment," and "building" facets are reported in Tables 4(a), 4(b), and 4(c), respectively. Note that the numbers off the diagonals in the matrices are not integers, though all symmetric pairs maintain the reciprocal conditions, as the pairwise comparisons are formed by calculating the experts' individual responses at each point of comparison in a geometric mean. The geometric mean approach is proposed by Saaty [16] to reconcile conflicting judgments when the group members may hold unequal levels of influence. This method is also adopted by both Lai et al. [17] and Wu et al. [18] to synthesize the relative weights over a hierarchy in AHP.

Table 5 summarizes the overall weight rankings of all the ten subcriteria in selecting a gas station to be transformed as self-service. The overall weight of each subcriterion is achieved by multiplying its individual subcriterion weight, from either one of Tables 4(a)-4(c), with the corresponding facet weight from Table 3. For example, the first subcriterion (SC1), average number of cars, owns an individual weight of 0.360 compared to other subcriteria in the traffic facet (weight 0.311 at level 2), and thus SC1 has an overall weight at 0.112 $(=0.36 \times 0.311)$ or $11.2 \%$ of importance. Table 5 concludes that the average amount of fuel consumption (SC4) in the environment facet is the most important with the highest overall weight of 0.152 and the least important subcriterion is floor area size (SC10), which weighs only 0.059 in the case problem. Complete sequences of ten subcriteria with descending importance are, at the first half, SC4, SC6, SC7, SC1, and SC3 and then SC2, SC5, SC8, SC9, and SC10 at the second half.

4.2. MCGP Modeling. To proceed to utilize the MCGP in selecting an ideal station to start self-service, DMs (managers of the case company) were asked to specify the minimum requirements to meet in each goal. Note that the goal priority in GP is set by the criterion importance obtained from AHP. The goal with the first priority is the criterion which weights the most; the second-priority goal is the criterion having the second largest weight, and so forth.

Goal 1. The average fuel consumption (SC4) must exceed 20,000 dL per day; the more, the better.

Goal 2. The average swipe rate (SC6) must exceed $10 \%$; the more, the better. 
TABle 4: (a) Pairwise comparison matrix for level 3 subcriteria at "traffic" facet. (b) Pairwise comparison matrix for level 3 subcriteria at "environment" facet. (c) Pairwise comparison matrix for level 3 subcriteria at "building" facet.

(a)

\begin{tabular}{lcccc}
\hline Subcriteria & Average number of cars & Average number of motorcycles & Waiting time & Weight \\
\hline Average number of cars & 1 & 1.060 & 1.190 \\
Average number of motorcycles & 0.943 & 1 & 0.360 \\
Waiting time & 0.840 & 1.111 & 0.900 \\
\hline \multicolumn{3}{c}{$\mathrm{CR}=0.046<0.1$} \\
\hline
\end{tabular}

(b)

\begin{tabular}{|c|c|c|c|c|c|}
\hline Subcriteria & Average fuel consumption & Number of competitors & Average swipe rate & Neighborhood acceptance & Weight \\
\hline Average fuel consumption & 1 & 1.680 & 1.283 & 1.241 & 0.309 \\
\hline Number of competitors & 0.595 & 1 & 0.447 & 0.609 & 0.155 \\
\hline Average swipe rate & 0.779 & 2.236 & 1 & 0.951 & 0.275 \\
\hline Neighborhood acceptance & 0.806 & 1.680 & 1.052 & 1 & 0.261 \\
\hline \multicolumn{6}{|c|}{$\mathrm{CR}=0.011<0.1$} \\
\hline
\end{tabular}

(c)

\begin{tabular}{|c|c|c|c|c|}
\hline Subcriteria & Number of gas pump islands & Number of gas pumps & Floor area or lot size & Weight \\
\hline Number of gas pump islands & 1 & 1.070 & 1.250 & 0.366 \\
\hline Number of gas pumps & 0.935 & 1 & 1.100 & 0.335 \\
\hline Floor area or lot size & 0.800 & 0.909 & 1 & 0.299 \\
\hline \multicolumn{5}{|c|}{$\mathrm{CR}=0.000<0.1$} \\
\hline
\end{tabular}

TABLE 5: Overall weights for 10 subcriteria and their weight rankings.

\begin{tabular}{|c|c|c|c|c|c|}
\hline Criteria (facet) & Facet weight & Subcriteria at level 3 & Subcriterion weight & Overall weight & Overall rank \\
\hline \multirow{3}{*}{ Traffic } & \multirow{3}{*}{0.311} & Average number of cars & 0.360 & 0.112 & 4 \\
\hline & & Average number of motorcycles & 0.315 & 0.098 & 6 \\
\hline & & Waiting time & 0.325 & 0.101 & 5 \\
\hline \multirow{4}{*}{ Environment } & \multirow{4}{*}{0.493} & Average fuel consumption & 0.309 & 0.152 & 1 \\
\hline & & Number of competitors & 0.155 & 0.076 & 7 \\
\hline & & Average swipe rate & 0.275 & 0.136 & 2 \\
\hline & & Neighborhood acceptance & 0.261 & 0.129 & 3 \\
\hline \multirow{3}{*}{ Building } & \multirow{3}{*}{0.196} & Number of gas pump islands & 0.366 & 0.072 & 8 \\
\hline & & Number of gas pumps & 0.335 & 0.066 & 9 \\
\hline & & Floor area size & 0.299 & 0.059 & 10 \\
\hline
\end{tabular}

Goal 3. The percentage of neighbors willing to accept the new technology (SC7) must exceed 30\%; the more, the better.

Goal 4. The average number of cars (SC1) must exceed 450 per day; the larger, the better.

Goal 5. The waiting time (SC3) should be less than 6 minutes, and, of course, less is better.

Goal 6. The average number of motorcycles (SC2) must exceed 1000 per day; the larger, the better.

Goal 7. The number of competitors (SC5) should be less than 13 , and, of course, less is better.

Goal 8. The number of gas pump islands (SC8) must exceed 3 ; the larger, the better.
Goal 9. The number of gas pumps (SC9) must exceed 4; the larger, the better.

Goal 10. The floor area size (SC10) must exceed 1100; the larger, the better.

We first eliminated those candidates that fail to meet the minimum requirements specified in each goal. In Table 2, the underlined data show that the average swipe rate (SC6) at $\mathrm{ST}_{3}$ is below $10 \%$, and the number of gas pump islands (SC8) at $\mathrm{ST}_{6}$ is less than three; that is, candidates $\mathrm{ST}_{3}$ and $\mathrm{ST}_{6}$ fail to satisfy Goal 2 and Goal 8, respectively. They were thus excluded from the list which the proposed MCGP method was applied to. By doing so, it can be more efficient to find a solution from the remaining six candidates. Then, to overcome the differences in measure units of different 
TABLE 6: Satisfaction membership function of the ten goals.

\begin{tabular}{|c|c|c|c|c|}
\hline Subcriterion/goal & Lowest & & & Highest \\
\hline (SC4) Average fuel consumption (dL) & 20000 & 28000 & 35000 & 41000 up \\
\hline Satisfaction level & 0.2 & 0.5 & 0.8 & 1 \\
\hline (SC6) Average swipe rate (\%) & 6 & 10 & 12 & 14 up \\
\hline Satisfaction level & 0.1 & 0.6 & 0.8 & 1 \\
\hline (SC7) Neighbor's acceptance (\%) & 20 & 40 & 60 & 80 up \\
\hline Satisfaction level & 0.1 & 0.4 & 0.7 & 1 \\
\hline (SC1) Average number of cars & 400 & 900 & 1500 & 1800 up \\
\hline Satisfaction level & 0.2 & 0.6 & 0.8 & 1 \\
\hline (SC3) Waiting time (min) & 6 & 5 & 4 & 2 below \\
\hline Satisfaction level & 0.2 & 0.5 & 0.8 & 1 \\
\hline (SC2) Average number of motorcycles & 1000 & 2000 & 3000 & 4000 up \\
\hline Satisfaction level & 0.2 & 0.5 & 0.8 & 1 \\
\hline (SC5) Number of competitors & 13 & 10 & 5 & 2 below \\
\hline Satisfaction level & 0.5 & 0.6 & 0.7 & 1 \\
\hline (SC8) Number of gas pump islands & 2 & 4 & 5 & 6 up \\
\hline Satisfaction level & 0.2 & 0.6 & 0.8 & 1 \\
\hline (SC9) Number of gas pumps & 3 & 4 & 5 & 6 up \\
\hline Satisfaction level & 0.6 & 0.8 & 0.9 & 1 \\
\hline$(\mathrm{SC} 10)$ Floor area size $\left(\mathrm{m}^{2}\right)$ & 1000 & 1300 & 1500 & 1600 up \\
\hline Satisfaction level & 0.5 & 0.7 & 0.9 & 1 \\
\hline
\end{tabular}

TABLE 7: Satisfaction levels for the remaining six candidates over the ten goals.

\begin{tabular}{|c|c|c|c|c|c|c|c|c|}
\hline \multirow{2}{*}{ Goal } & \multirow{2}{*}{ Weights } & \multirow{2}{*}{ Minimum levels } & \multicolumn{6}{|c|}{ Locations } \\
\hline & & & $\mathrm{ST}_{1}$ & $\mathrm{ST}_{2}$ & $\mathrm{ST}_{4}$ & $\mathrm{ST}_{5}$ & $\mathrm{ST}_{7}$ & $\mathrm{ST}_{8}$ \\
\hline Goal 1 (SC4) & 0.152 & $\geq 0.2$ & 0.22 & 0.32 & 0.98 & 0.95 & 0.31 & 0.87 \\
\hline Goal 2 (SC6) & 0.136 & $\geq 0.6$ & $\overline{0.8}$ & 1 & 0.6 & 0.7 & 0.7 & 0.9 \\
\hline Goal 3 (SC7) & 0.129 & $\geq 0.25$ & 0.4 & 0.7 & 0.85 & 0.7 & 0.4 & 0.55 \\
\hline Goal 4 (SC1) & 0.112 & $\geq 0.24$ & 0.3 & 1 & 0.73 & 0.64 & 0.36 & 0.26 \\
\hline Goal 5 (SC3) & 0.101 & $\geq 0.2$ & 1 & 0.5 & 0.8 & 0.8 & 0.9 & 0.3 \\
\hline Goal 6 (SC2) & 0.098 & $\geq 0.2$ & 0.29 & 0.64 & 0.6 & 1 & 0.28 & 0.23 \\
\hline Goal 7 (SC5) & 0.076 & $\geq 0.5$ & 0.7 & 0.6 & 0.68 & 0.5 & 1 & 0.9 \\
\hline Goal 8 (SC8) & 0.072 & $\geq 0.4$ & 0.6 & 0.8 & 0.4 & 0.4 & 0.6 & 0.6 \\
\hline Goal 9 (SC9) & 0.066 & $\geq 0.8$ & 1 & 1 & 1 & 1 & 1 & 1 \\
\hline Goal 10 (SC10) & 0.059 & $\geq 0.57$ & 0.92 & 0.68 & 1 & 1 & 0.61 & 0.58 \\
\hline \multicolumn{3}{|c|}{ Weighted satisfaction levels over 10 goals } & 0.5735 & 0.7095 & 0.7671 & 0.7722 & 0.5738 & 0.6194 \\
\hline
\end{tabular}

goals and make it possible to compare data from different categories, we adopted the satisfaction membership function, developed by Zadeh [19], which maps data into satisfaction levels ranging from zero to one. To compare those candidate locations, we identified their satisfaction (or aspiration) levels on each goal based on DMs' subjective preferences and evaluation consensus such as "the more, the better." For example, for Goal 1 or SC4, if the average fuel consumption reaches $35000 \mathrm{dL}$, the satisfaction level would be 0.8 ; the satisfaction level would be 1 if the fuel consumption reaches $41000 \mathrm{dL}$. However, if "less is better" is remarked in Goal 5 or SC3, for instance, then higher source data obtains a lower satisfaction level instead. Table 6 lists how the original data of all subcriteria correspond to different satisfaction levels in the order of goal priority. Note that the lowest satisfaction levels of different goals may differ.

A piecewise linear interpolation was then applied to estimate the corresponding satisfaction level on each goal. Table 7 summarizes the results for each of the six candidates under consideration, in which their weighted satisfaction levels over the ten goals are reported at the bottom. For example, the italic number next to SC4 (or Goal 1) in Table 2 shows that the full-service gas station $\mathrm{ST}_{1}$ originally owned fuel consumption at an average of $20479 \mathrm{dL}$ every day. We applied a linear interpolation or proportional estimate to the source data by using the satisfaction membership function of 
Goal 1 (in Table 6) and got the satisfaction level $\underline{0.22}$ shown on the upper part of Table 7. The transformation is justified as follows:

$$
\left(0.2+\frac{(0.5-0.2) *(20479-20000)}{(28000-20000)}\right)=0.22
$$

To continue to formulate the case problem in a MCGP model, we refer readers to the general modeling in Section 3.2 , to which six binary variables $(m=6)$ and ten goals $(n=10)$ are applied. The associated decision variables and deviation variables are defined as follows:

$x_{j}$ : binary variable to represent whether or not the station $\mathrm{ST}_{j}$ is selected; if $x_{j}=1$, then $\mathrm{ST}_{j}$ is selected; if $x_{j}=0$, then $\mathrm{ST}_{j}$ is not selected, $j=1,2,4,5,7$, and 8 .

$g_{i}$ : the satisfaction (or aspiration) level to meet in Goal $i, i=1, \ldots, 10$.

$d_{i}^{+}, d_{i}^{-} \geq 0$ : over- and underchievements of the $i$ th goal, $i=1, \ldots, 10$.

$e_{i}^{+}, e_{i}^{-} \geq 0$ : positive and negative deviations between the realized satisfaction level and its maximum in the $i$ th goal, $i=1, \ldots, 10$.

The objective function is formulated in (3). It aims to minimize the sum of goal deviations and the differences between the realized satisfaction levels and the maximal ones. Note that each positive deviation term is multiplied by its corresponding subcriterion weight; thus, terms with negative deviation are to be minimized with priority as they all have larger weights than their counterparts. Hence,

$$
\begin{aligned}
\operatorname{Min} & 0.152 \cdot d_{1}^{+}+d_{1}^{-}+0.136 \cdot d_{2}^{+}+d_{2}^{-}+0.129 \cdot d_{3}^{+} \\
& +d_{3}^{-}+0.112 \cdot d_{4}^{+}+d_{4}^{-}+d_{5}^{+}+0.101 \cdot d_{5}^{-} \\
& +0.098 \cdot d_{6}^{+}+d_{6}^{-}+d_{7}^{+}+0.076 \cdot d_{7}^{-}+0.072 \\
& \cdot d_{8}^{+}+d_{8}^{-}+0.066 \cdot d_{9}^{+}+d_{9}^{-}+0.059 \cdot d_{10}^{+}+d_{10}^{-} \\
& +\left(e_{1}^{+}+e_{1}^{-}\right)+\left(e_{2}^{+}+e_{2}^{-}\right)+\left(e_{3}^{+}+e_{3}^{-}\right)+\left(e_{4}^{+}+e_{4}^{-}\right) \\
& +\left(e_{5}^{+}+e_{5}^{-}\right)+\left(e_{6}^{+}+e_{6}^{-}\right)+\left(e_{7}^{+}+e_{7}^{-}\right)+\left(e_{8}^{+}+e_{8}^{-}\right) \\
& +\left(e_{9}^{+}+e_{9}^{-}\right)+\left(e_{10}^{+}+e_{10}^{-}\right)
\end{aligned}
$$

Only one station among the six candidates not containing $\mathrm{ST}_{3}$ and $\mathrm{ST}_{6}$ is to be selected, and this can be formulated as (4). Note that the decision variables are binary. Hence,

$$
x_{1}+x_{2}+x_{4}+x_{5}+x_{7}+x_{8}=1 \text {. }
$$

We then continue to address the constraints for each goal in decreasing priority. The first goal states that the average fuel consumption (SC4) must exceed $20,000 \mathrm{dL}$ or 0.2 in satisfaction level. Equation (5) represents the notion that the selected gas station has the realized satisfaction level $g_{1}$ for Goal 1; it is formed by the decision variables and all the candidates' satisfaction levels with respect to SC4 (in Table 7). Equation (6) indicates differences between the realized and highest satisfaction levels. Finally, (7) depicts the range of satisfaction levels associated with Goal 1. Therefore, one has

$$
\begin{aligned}
& 0.22 x_{1}+0.32 x_{2}+0.98 x_{4}+0.95 x_{5}+0.31 x_{7}+0.87 x_{8} \\
& \quad-d_{1}^{+}+d_{1}^{-}=g_{1}, \\
& g_{1}-e_{1}^{+}+e_{1}^{-}=1, \\
& 0.2 \leq g_{1} \leq 1 .
\end{aligned}
$$

Similarly, in a group of three equations, constraints for Goal 2 (swipe rate above 10\%) to Goal 10 (floor size over $1100 \mathrm{~m}^{2}$ ) are formulated, respectively, as follows:

$$
\begin{aligned}
& 0.8 x_{1}+x_{2}+0.6 x_{4}+0.7 x_{5}+0.7 x_{7}+0.9 x_{8}-d_{2}^{+}+d_{2}^{-} \\
& =g_{2} \\
& g_{2}-e_{2}^{+}+e_{2}^{-}=1 \\
& 0.6 \leq g_{2} \leq 1 \\
& 0.4 x_{1}+0.7 x_{2}+0.85 x_{4}+0.7 x_{5}+0.4 x_{7}+0.55 x_{8}-d_{3}^{+} \\
& +d_{3}^{-}=g_{3} \\
& g_{3}-e_{3}^{+}+e_{3}^{-}=1 \\
& 0.25 \leq g_{3} \leq 1 \\
& 0.3 x_{1}+x_{2}+0.73 x_{4}+0.64 x_{5}+0.36 x_{7}+0.26 x_{8}-d_{4}^{+} \\
& +d_{4}^{-}=g_{4} \\
& g_{4}-e_{4}^{+}+e_{4}^{-}=1 \\
& 0.24 \leq g_{4} \leq 1 \\
& x_{1}+0.5 x_{2}+0.8 x_{4}+0.8 x_{5}+0.9 x_{7}+0.3 x_{8}-d_{5}^{+}+d_{5}^{-} \\
& =g_{5} \\
& g_{5}-e_{5}^{+}+e_{5}^{-}=1 \\
& 0.2 \leq g_{5} \leq 1 \\
& 0.29 x_{1}+0.64 x_{2}+0.6 x_{4}+x_{5}+0.28 x_{7}+0.23 x_{8}-d_{6}^{+} \\
& +d_{6}^{-}=g_{6} \\
& g_{6}-e_{6}^{+}+e_{6}^{-}=1 \\
& 0.2 \leq g_{6} \leq 1 \\
& 0.7 x_{1}+0.6 x_{2}+0.68 x_{4}+0.5 x_{5}+x_{7}+0.9 x_{8}-d_{7}^{+} \\
& +d_{7}^{-}=g_{7} \\
& g_{7}-e_{7}^{+}+e_{7}^{-}=1
\end{aligned}
$$


TABLE 8: Solution outputs for the case problem.

\begin{tabular}{|c|c|c|c|c|c|}
\hline \multirow{2}{*}{$\begin{array}{l}\text { Decisions on candidate stations } \\
x_{1}=0\end{array}$} & \multirow{2}{*}{$\begin{array}{c}\text { Realized satisfaction level } \\
g_{1}=0.98\end{array}$} & \multicolumn{2}{|c|}{ Deviations from the goal } & \multicolumn{2}{|c|}{ Satisfaction level deviations } \\
\hline & & $d_{1}^{+}=0$ & $d_{1}^{-}=0$ & $e_{1}^{+}=0$ & $e_{1}^{-}=0.02$ \\
\hline \multirow[t]{2}{*}{$x_{2}=0$} & $g_{2}=0.6$ & $d_{2}^{+}=0$ & $d_{2}^{-}=0$ & $e_{2}^{+}=0$ & $e_{2}^{-}=0.4$ \\
\hline & $g_{3}=0.85$ & $d_{3}^{+}=0$ & $d_{3}^{-}=0$ & $e_{3}^{+}=0$ & $e_{3}^{-}=0.15$ \\
\hline$x_{4}=1$ & $g_{4}=0.73$ & $d_{4}^{+}=0$ & $d_{4}^{-}=0$ & $e_{4}^{+}=0$ & $e_{4}^{-}=0.27$ \\
\hline \multirow{2}{*}{$x_{5}=0$} & $g_{5}=1$ & $d_{5}^{+}=0$ & $d_{5}^{-}=0.2$ & $e_{5}^{+}=0$ & $e_{5}^{-}=0$ \\
\hline & $g_{6}=1$ & $d_{6}^{+}=0.66$ & $d_{6}^{-}=0$ & $e_{6}^{+}=0$ & $e_{6}^{-}=0$ \\
\hline$x_{7}=0$ & $g_{7}=1$ & $d_{7}^{+}=0$ & $d_{7}^{-}=0.32$ & $e_{7}^{+}=0$ & $e_{7}^{-}=0$ \\
\hline \multirow[t]{3}{*}{$x_{8}=0$} & $g_{8}=0.4$ & $d_{8}^{+}=0$ & $d_{8}^{-}=0$ & $e_{8}^{+}=0$ & $e_{8}^{-}=0.6$ \\
\hline & $g_{9}=1$ & $d_{9}^{+}=0$ & $d_{9}^{-}=0$ & $e_{9}^{+}=0$ & $e_{9}^{-}=0$ \\
\hline & $g_{10}=1$ & $d_{10}^{+}=0$ & $d_{10}^{-}=0$ & $e_{10}^{+}=0$ & $e_{10}^{-}=0$ \\
\hline
\end{tabular}

$$
\begin{aligned}
& 0.6 x_{1}+0.8 x_{2}+0.4 x_{4}+0.4 x_{5}+0.6 x_{7}+0.6 x_{8}-d_{8}^{+} \\
& \quad+d_{8}^{-}=g_{8} \\
& g_{8}-e_{8}^{+}+e_{8}^{-}=1 \\
& 0.4 \leq g_{8} \leq 1 \\
& x_{1}+x_{2}+x_{4}+x_{5}+x_{7}+x_{8}-d_{9}^{+}+d_{9}^{-}=g_{9} \\
& g_{9}-e_{9}^{+}+e_{9}^{-}=1 \\
& 0.8 \leq g_{9} \leq 1 \\
& 0.92 x_{1}+0.68 x_{2}+x_{4}+x_{5}+0.61 x_{7}+0.58 x_{8}-d_{10}^{+} \\
& \quad+d_{10}^{-}=g_{10} \\
& g_{10}-e_{10}^{+}+e_{10}^{-}=1 \\
& 0.57 \leq g_{10} \leq 1 .
\end{aligned}
$$

4.3. Results. As the above MCGP model is linear with 58 variables in total, it can be easily solved by using common linear programming packages such as the LINGO software. Table 8 lists all the outputs. Solutions for the binary decision variables include $x_{4}=1$ and all the other $x_{i}$ 's are zeros. All goal deviations $d_{i}^{+}$'s and $d_{i}^{-}$'s are zeros, for $i=1, \ldots, 10$, except $d_{5}^{-}=0.2, d_{6}^{+}=0.66$, and $d_{7}^{-}=0.32$. However, half of the ten goals in consideration attain the highest satisfaction levels; namely, $g_{5}, g_{6}, g_{7}, g_{9}$, and $g_{10}$ are all ones; this means $\mathrm{ST}_{4}$ is the "most satisfactory" solution in that, besides satisfying all goals, it achieves the satisfaction levels as high as possible.

Once the solution $\mathrm{ST}_{4}$ is removed for the second iteration, the proposed MCGP model can be applied accordingly to the remaining five sites. The "second best" location is finally known to be $\mathrm{ST}_{5}$. Again, repeat the MCGP model to the remaining four candidates $\mathrm{ST}_{1}, \mathrm{ST}_{2}, \mathrm{ST}_{7}$, and $\mathrm{ST}_{8}$, and the solution in the third iteration is $\mathrm{ST}_{2}$. We conclude that, by applying repeatedly the MCGP to the case problem, solutions with the highest satisfaction level in three rounds are first $\mathrm{ST}_{4}$ and then $\mathrm{ST}_{5}$ and finally $\mathrm{ST}_{2}$.

\section{Discussion}

The proposed MCGP method finds that $\mathrm{ST}_{4}$ is the "most satisfactory" location to be transformed into a self-service gas station and $\mathrm{ST}_{5}$ ranks the second. However, results may be different if a different method such as the simple additive weighting (SAW) is utilized. As shown at the bottom row of Table 7, any candidate's weighted satisfaction level can be calculated by applying SAW to AHP importance weights over the ten goals, namely, 0.152 for Goal 1, 0.136 for Goal 2, and so on. From the results, $\mathrm{ST}_{4}$ has a slightly lower weighted satisfaction level at 0.7671 than that of $\mathrm{ST}_{5}$ at 0.7722 ; hence, $\mathrm{ST}_{4}$ can only rank second if evaluated by SAW instead.

In fact, candidate $\mathrm{ST}_{5}$ is located in downtown Kaohsiung, the biggest city in southern Taiwan. It is centered at the business zones and night markets. On the other hand, $\mathrm{ST}_{4}$ is located in the Kaohsiung industrial zone, where two highways intersect and many petrochemistry and information technology companies are housed. Geographically, gas stations $\mathrm{ST}_{4}$ and $\mathrm{ST}_{5}$ have their own advantages as being transformed to be self-service. Actually, results in Table 7 show that both even tie in Goals 5 (waiting time) and 8 to 10 (number of islands, number of gas pumps, and floor area, resp.) though $\mathrm{ST}_{4}$ attains higher satisfaction levels in Goals 1 (fuel consumption), 3 (neighbor's acceptance), 4 (number of cars), and 7 (number of competitors) while $\mathrm{ST}_{5}$ outperforms $\mathrm{ST}_{4}$ in the remaining two subcriteria: swipe rate and number of motorcycles.

The weighted method and the GP have different results for the problem though $\mathrm{ST}_{4}$ and $\mathrm{ST}_{5}$ are almost on a par. There are many multicriteria methods for solving decisionmaking problems. However, different methods usually conclude distinct rankings of the alternatives even for the same selection problem [20]. In the analysis of multicriteria decision-making methods, Velasquez and Hester [21] pointed out that the SAW method is intuitive to decision-makers and easy to use, but it may not reflect the real situations and obtain logical results. Used in combination with other methods such as AHP to weight coefficients, GP can cope with the disadvantages of the SAW method though calculation in GP is not simple. Furthermore, the proposed MCGP method is even superior to the GP model since it is equipped with the 
multichoice functions which vary satisfaction levels in the predefined goals [22].

\section{Conclusions}

Location selection of a gas station is important to managers in business decision-making and to the neighborhood in acceptance of new equipment utilities. It is thus needed to be carefully considered including qualitative and quantitative criteria simultaneously. Core criteria of the "optimal" selection of location for gas station renovation in this study are traffic, environment, and building. In the AHP evaluation process, the weights of three criteria and 10 subcriteria for the case problem were presented. From the results, the most important factors (subcriteria) are average fuel consumption, average swipe rate, and neighborhood acceptance, all in the environment criteria, and, accordingly, the average number of cars in the traffic criteria. Hence, DMs can pay more attention to the fuel consumption, swipe rate, and neighborhood acceptance while surveying a gas station for selfservice operations. In addition, a MCGP model integrating the weights obtained by AHP was formulated to justify the most suitable location that can meet as many goals and as maximal aspiration levels as possible. The solution procedure can also be a guideline for the case company's investment decisions in enhancing the utilization in each self-service gas station.

This study presents an AHP-MCGP method that aids DMs to apply appropriate weights from AHP to the objective function of MCGP in the location selection problem considering both qualitative and quantitative criteria. The proposed model can integrate opinions about weight settings among goals from several DMs using AHP. Their opinions can be integrated into aspiration of each goal in the MCGP method. The solution procedure is systematic and objective and it can be developed as a decision support system (DSS). With the tailored DSS, the proposed approach can thus be adopted in solving not only location selection, but also general decision problems.

\section{Competing Interests}

The authors declare that there are no competing interests regarding the publication of this paper.

\section{References}

[1] S. Adsavakulchai and C. Huntula, "Optimum site selection of natural gas vehicles station in Bangkok using geographic information system," Journal of Petroleum and Gas Engineering, vol. 1, no. 5, pp. 89-94, 2010.

[2] M. Aslani and A. A. Alesheikh, "Site selection for small gas stations using GIS," Scientific Research and Essays, vol. 6, no. 15, pp. 1361-3171, 2011

[3] G.-H. Tzeng, M.-H. Teng, J.-J. Chen, and S. Opricovic, "Multicriteria selection for a restaurant location in Taipei," International Journal of Hospitality Management, vol. 21, no. 2, pp. 171187, 2002.
[4] H. Aras, Ş. Erdoğmuş, and E. Koç, "Multi-criteria selection for a wind observation station location using analytic hierarchy process," Renewable Energy, vol. 29, no. 8, pp. 1383-1392, 2004.

[5] J. K. W. Wong and H. Li, "Application of the analytic hierarchy process (AHP) in multi-criteria analysis of the selection of intelligent building systems," Building and Environment, vol. 43, no. 1, pp. 108-125, 2008.

[6] M. Uyan, "GIS-based solar farms site selection using analytic hierarchy process (AHP) in Karapinar region Konya/Turkey," Renewable and Sustainable Energy Reviews, vol. 28, pp. 11-17, 2013.

[7] D. M. Jovanovic, "Planning of optimal location and sizes of distribution transformers using integer programming," International Journal of Electrical Power and Energy System, vol. 25, no. 9, pp. 717-723, 2003.

[8] E. W. L. Cheng and H. Li, "Exploring quantitative methods for project location selection," Building and Environment, vol. 39, no. 12, pp. 1467-1476, 2004.

[9] A. Charnes and W. W. Cooper, "Management models and industrial applications of linear programming," Management Science, vol. 4, no. 1, pp. 38-91, 1957.

[10] J. R. San Cristóbal, “A goal programming model for the optimal mix and location of renewable energy plants in the north of Spain," Renewable and Sustainable Energy Reviews, vol. 16, no. 7, pp. 4461-4464, 2012.

[11] C.-T. Chang, "Multi-choice goal programming," Omega, vol. 35, no. 4, pp. 389-396, 2007.

[12] C.-N. Liao and H.-P. Kao, "Supplier selection model using Taguchi loss function, analytical hierarchy process and multichoice goal programming," Computers \& Industrial Engineering, vol. 58, no. 4, pp. 571-577, 2010.

[13] H.-P. Ho, C.-T. Chang, and C.-Y. Ku, "On the location selection problem using analytic hierarchy process and multi-choice goal programming," International Journal of Systems Science, vol. 44, no. 1, pp. 94-108, 2013.

[14] T.-C. Lin, H.-P. Ho, and C.-T. Chang, "Evaluation model for applying an e-learning system in a course: an analytic hierarchy process-multi-choice goal programming approach," Journal of Educational Computing Research, vol. 50, no. 1, pp. 135-157, 2014.

[15] T. L. Saaty, The Analytical Hierarchical Process, John Wiley \& Sons, New York, NY, USA, 1980.

[16] T. L. Saaty, "How to make a decision: the analytic hierarchy process," European Journal of Operational Research, vol. 48, no. 1, pp. 9-26, 1990.

[17] V. S. Lai, B. K. Wong, and W. Cheung, "Group decision making in a multiple criteria environment: a case using the AHP in software selection," European Journal of Operational Research, vol. 137, no. 1, pp. 134-144, 2002.

[18] C.-R. Wu, C.-T. Lin, and H.-C. Chen, "Optimal selection of location for Taiwanese hospitals to ensure a competitive advantage by using the analytic hierarchy process and sensitivity analysis," Building and Environment, vol. 42, no. 3, pp. 14311444, 2007.

[19] L. A. Zadeh, "Fuzzy sets," Information and Control, vol. 8, no. 3, pp. 338-353, 1965.

[20] J. Thor, S. H. Ding, and S. Kamaruddin, "Comparison of multi criteria decision making methods from the maintenance alternative selection perspective," The International Journal of Engineering and Science, vol. 2, no. 6, pp. 27-34, 2013. 
[21] M. Velasquez and P. T. Hester, "An analysis of multi-criteria decision making methods," International Journal of Operations Research, vol. 10, no. 2, pp. 56-66, 2013.

[22] C.-T. Chang, "Multi-choice goal programming model for the optimal location of renewable energy facilities," Renewable and Sustainable Energy Reviews, vol. 41, pp. 379-389, 2015. 


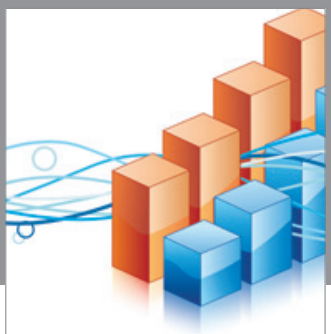

Advances in

Operations Research

vatem alat4

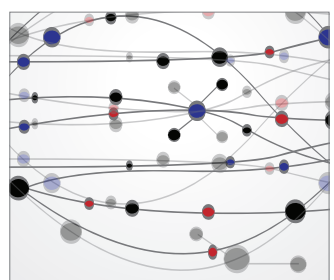

\section{The Scientific} World Journal
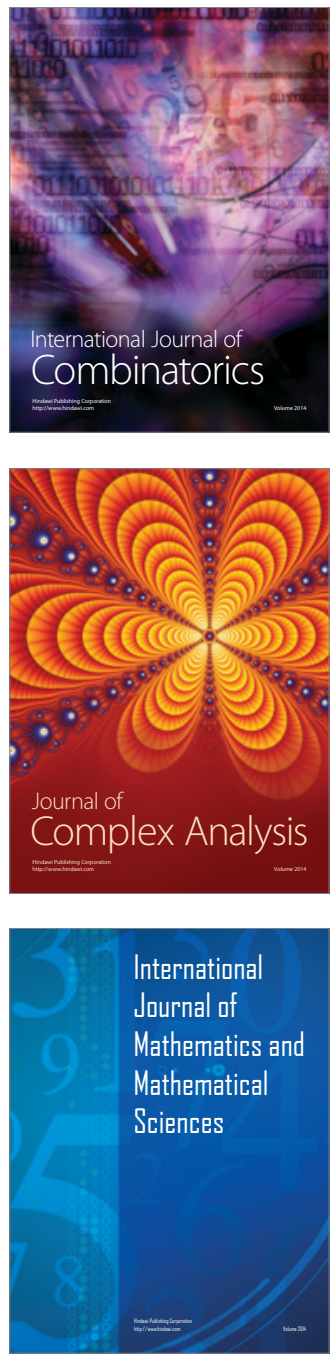
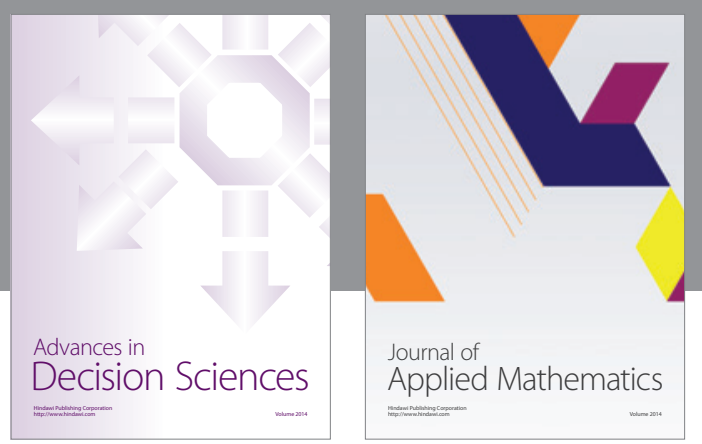

Algebra

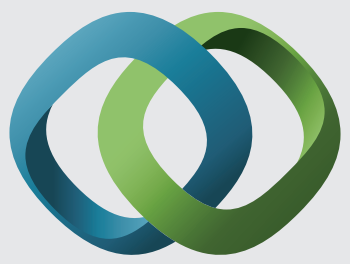

\section{Hindawi}

Submit your manuscripts at

http://www.hindawi.com
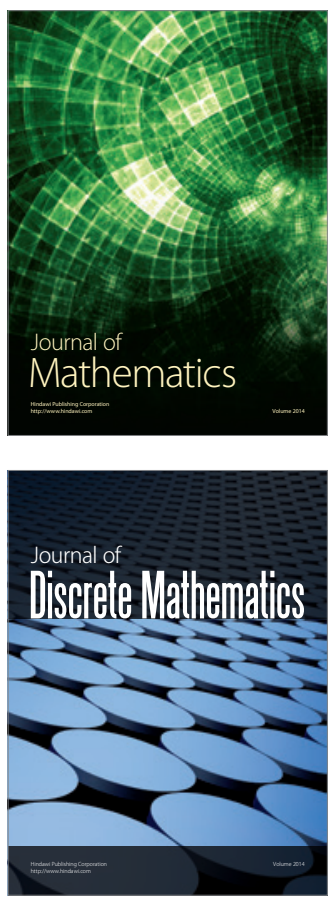

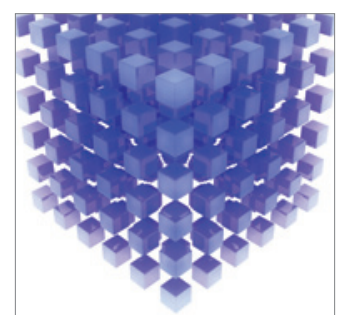

Mathematical Problems in Engineering
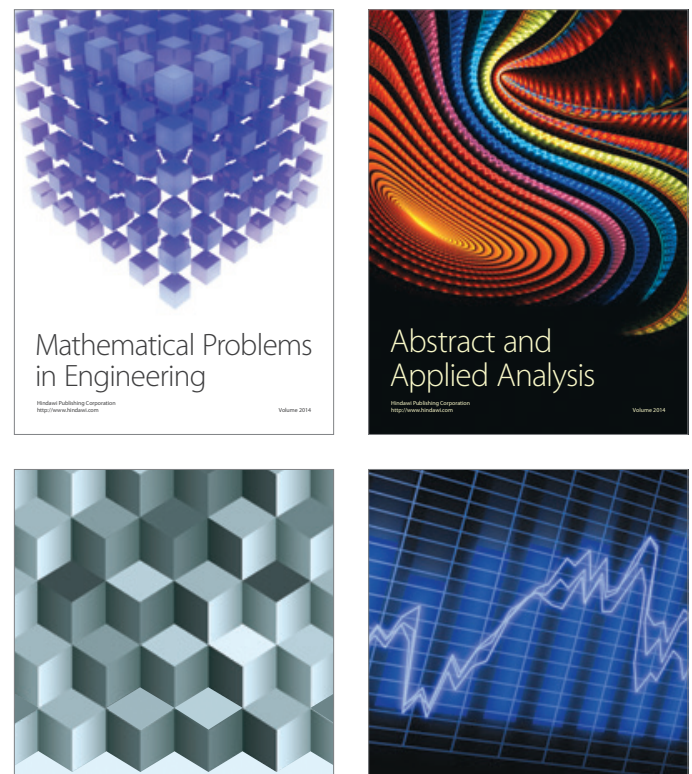

Journal of

Function Spaces

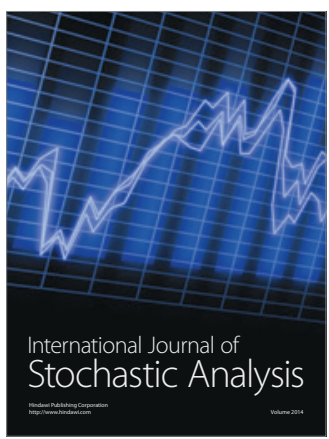

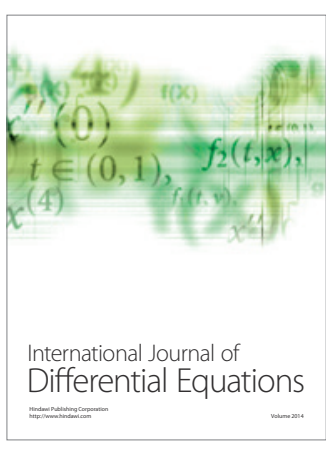
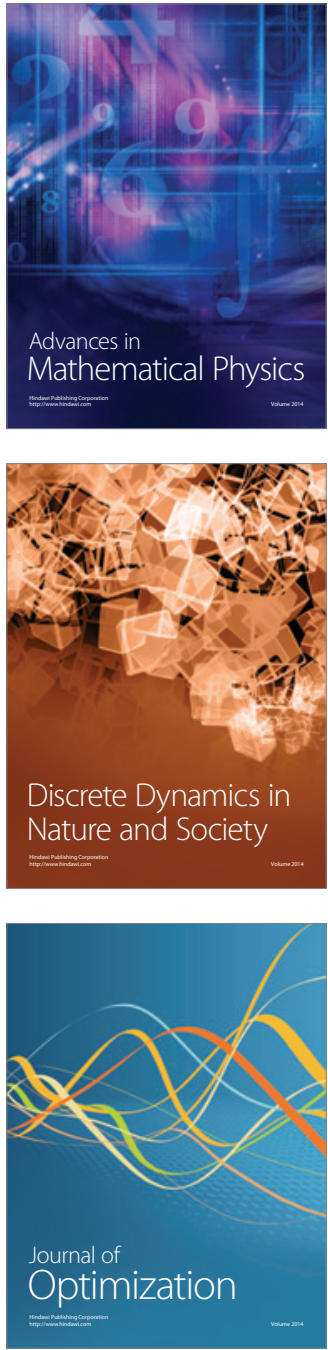